\title{
AAIB \& CSR in Egypt: A 10 year Review!
}

\author{
Menatallah Darrag ${ }^{1}$ and Reham El Seidi ${ }^{2}$ \\ ${ }^{1}$ International Business Department German University, Cairo \\ ${ }^{2}$ Marketing Department Ain Shams University, Cairo
}

Correspondence should be addressed to: Menatallah Darrag; sdarrag@hotmail.com

Received date: 21 March 2012; Accepted date: 26 August 2014; Published date: 15 January 2015

Academic Editor: Rasha Fady Ismail

Copyright (C) 2015. Menatallah Darrag and Reham El Seidi. Distributed under Creative Commons CC-BY 4.0

\begin{abstract}
Though the CSR concept had started to attract scholars' attention from Bowen's writings in the 1950s, it remained an under researched topic in developing countries. Emphasis on CSR had begun when the international standards \& protocols (i.e. SA 8000 \& Global Responsibility Initiative), indexes (i.e. FTSE4Good \& Dow Jones Sustainability Index) \& conventions (i.e. UN Global Compact) had started to gain increased endorsement from varying organizations \& communities operating across different countries. Moreover, as the stakeholder theory had gained major literature support within the CSR area, it serves well to identify this concept within a developing country's context, like Egypt giving a banking organizational experience; Arab African International Bank (AAIB); that was turned into a successful value-creation operation to all involved stakeholders. In-depth interviewing was conducted with the CSR Head within AAIB, along with siding to different organizational publications to deduce \& analyze the information acquired \& presented within the case. Further to that, AAIB's experience postulates a remarkable one as it reflects the CSR operations in Egypt pre the turning point of 2011, which would serve in setting a benchmark of comparisons later on due to the fact that CSR activities are now under high scrutiny \& public questioning in relevance to their hidden agendas \& objective
\end{abstract}

Keyword: AAIB ; CSR

Cite this Article as: Menatallah Darrag and Reham El Seidi (2015), " AAIB \& CSR in Egypt: A 10 year Review! “ The MENA Journal of Business Case Studies, Vol. 2015 (2015), Article ID 203993, DOI: 10.5171/2015. 203993 


\section{Introduction}

The banking sector stands as the foundation of the cash authority for the achievement of political and economic objectives of a country and acts as the main channel from which the financial dealings among other economic sectors pour into. Thus, investigation of the role played by banks; especially commercial ones; in the development of national economy receives great interest by those concerned about development issues in Egypt (Nassar and Mandour, 2000). Such rationale stems from the fact that commercial banks are the lifeblood of economy in any country where deposits and savings accumulate and flow as a loan and credits for the various sectors contributing eventually to progress and economic development.

As the doctrine of Corporate Social Responsibility (CSR) has emerged and developed rapidly as a field of study ever since the1950s, the topic has earned substantial attention. The broadest definition of CSR refers to the relationship of corporation with society as a whole to enhance the critical social and economic situation. However, this concept still remains an under researched topic in developing countries such as Egypt.

Nowadays, the CSR and its activities are an important aspect for all the corporations over the world. Thus, many organizations are trying to implement CSR for several reasons as: (1) building trust in business and establish new forms which create value based on addressing societal challenges; (2) strengthening brand positioning; (3) enhancing corporate image and reputation; (4) increasing the ability to attract, motivate and retain employees; (5) decreasing operating cost and (6) representing a transition towards a new system where competitiveness and sustainable development become indistinguishable, etc (Kapoor and Sandhu, 2010 and Kotler \& Lee, 2005).
Moreover, after the $25^{\text {th }}$ revolution 2011, Egypt stands in a critical position and in real need of contributions and efforts through the banking sector to enhance value creation for all stakeholders to improve the critical social and economic situation that Egypt is facing these days.

One bank that has a commitment toward the Egyptian community and the work environment is the Arab African International Bank (AAIB). AAIB started out in 1964 with US\$ $100,000,000$ paid up capital, where it was established by a special law as the first Arab multinational bank in Egypt. The main shareholders were Kuwait Investment Authority (KIA) \& Central Bank of Egypt (CBE), each owning $49.37 \%$ in a joint-venture format. These powerful institutions lend in valuable support and credibility to the financial services offered by the bank. Currently, AAIB has 47 local branches \& 3 foreign ones in UAE \& Lebanon.

AAIB is gaining significant momentum towards assuming a leading position among Egyptian banks, which became one of the fastest growing banks in Egypt where AAIB's vision had been manifested in its practical retail breakthrough operations "To be the leading financial group in Egypt providing innovative services with a strong regional presence being the gateway for international business into the region" (AAIB, 2010).

A main landmark in AAIB's history came to be in 2002, where a turning point in strategic direction from the regular banking sector had been embarked. AAIB identified that their duties towards its achievements and responsibilities should not only grow financially, but should also develop a deeper commitment to help the growth of the community and encompass its contribution to stakeholders as a whole reflecting a moral mission to society and to bring about sustainable improvements in the community. In others words, AAIB adopted and identified CSR "To be a bank that grows with integrity, morality \& accountability; a bank that readily acknowledges its responsibility towards all its 
stakeholders \& lives up to its duties with both eagerness \& passion" (AAIB, 2010) Thus, AAIB's CSR is about value creation; reflecting an opportunity \& investment rather than a cost or risk which acts as an effective formula to generate a win-win situation for all stakeholders. For AAIB, responsible business goes beyond what is required by law to make a positive impact on society and the environment through their management, operations and products and through their engagement with stakeholders including employees, customers, investors, communities. Therefore, the commitment toward CSR is an obligation not an option for AAIB.

AAIB focuses on how to integrate strategic CSR initiatives within its business practices in key functional areas and produce measurable indexes. In 2005, AAIB established the CSR unit first within the marketing and communications department and later it became a separate unit. The main purpose for this unit is to coordinate and synthesize broad sustainability policies inline with bank's overall strategy. Thus, the CSR unit plays a significant role in enriching the bank's full resources, and creating a positive impact for both AAIB internally and externally. Internally, it provides on-going internal updates about CSR programs \& activities, develops structural policies and procedures, and submits progress reports to the global compact. Externally, the unit has developed many CSR programs and activities to engage various stakeholders.

\section{CSR Regulatory Milestones}

As such, AAIB has developed CSR regulatory Milestones reflecting stages of CSR adoption for corporations, moving from a mere option to adopting regulatory frameworks, to accommodating to market pressures, complying with governmental encouragement, along with investment policies to end up with law compliance (Figure 1).

\section{CSR Regulatory Milestones}

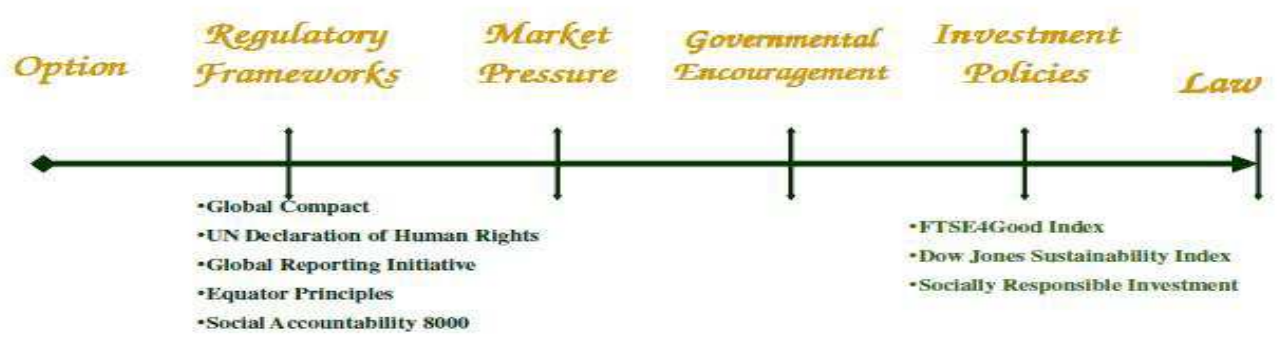

Figure 1: AAIB's CSR Regulatory Milestones (AAIB, 2010: 10)

As AAIB had decided to adopt the option of opting towards CSR activities, it ventured into the other milestones of CSR favoring CSR as no longer an option. AAIB adopted regulatory international frameworks such as the United Nations Global Compact principles, and other CSR groups such as The
London Benchmarking Group (LBG) and The Equator Principles (EP) along with their businesses values such as Customer Delight, Distinction, Dynamism, Empowerment, Passion and Patriotism. AAIB became a member since 2005 in The UN Global Compact, where it became committed to aligning its operations and strategies with ten universally accepted principles in the 
areas of human rights, labor, environment and anti-corruption. In 2007, AAIB joined the LBG global network of over 100 companies, as the first measurement, most comprehensive and widely used benchmarking means of valuing, managing, measuring and reporting Corporate Community Investment (CCI) whereby LBG focuses more on what companies achieve as opposed to how much they spend. On January 2009, AAIB became the first Equator Bank in Egypt, and the second in the region, by adopting the EP. In this, AAIB is set on integrating social and environmental risk management into its corporate finance deals. Currently, AAIB is trying to develop a MENA region outreach for the banking sector for landing approach to attend environmental social and financial sustainability

Market pressures could be manifested in different crisis situations that banks face (i.e. financial, global, humanitarian crises). Countermeasures have to be undertaken to secure a safe passage out of such crisis with minimal damages which protects multiple stakeholders' interests.

This was manifested in the 2009 financial crisis and the measures undertaken by the banking sector worldwide. A clear example is the direction of anti-corruption that is highly shown in Egyptian society after the $25^{\text {th }}$ of January 2011 revolution. Such direction created pressure driving corporations to enact their roles in endorsing societal activities benefiting multiple stakeholders that exceed the profit-maximizing behaviors of regular financial institutions.

Governmental Encouragement and Investment policies came into play in 2010. In that year, the Egyptian government through the Egyptian Corporate Responsibility Center (ECRC), which is a joint project between United Nations Development Program (UNDP) and Egyptian Institute of Directors (EIoD) affiliated with the Ministry of Investment and created the 1st Egyptian CSR indicator. It was conducted in collaboration with the Cairo-Alexandria Stock
Exchange, using S\&P's methodology. The indicator demonstrated leadership on environmental, social and corporate governance and became known as (ESG). Mainly the top 100 companies enlisted in the EGX were surveyed in a three-stage process and eventually the S\&P/EGX ESG index was created. This index embarks a new era for improving sustainability and transparency in Egypt and set priorities for investor engagement along with enhancing corporate governance (Zeitoun, 2010). These acts highlight the importance the Egyptian government places on CSR and thereby reflected in the stock market. By turn, AAIB and other corporations had identified such importance and would strive to comply with such standards. Thus far, CSR in Egypt had not been translated into laws, which is the last milestone.

\section{Value Creation \& Multiple Stakeholders}

Abdallah, H., Vice Chairman \& Managing Director identified that "With a constantly maturing understanding of corporate social responsibility, we become more and more inclined to believe it is about value creation" (AAIB, 2010: 6).

To that effect, AAIB, shares the belief that CSR is about value creation and can be seen as an ecosystem that is enriched only with genuine engagement of all its multiple stakeholders. However, the most important step for AAIB was to identify their key stakeholders who will serve as well as benefit from them to dedicate the CSR programs towards them in order to find creative and value-added solutions to societal and environmental challenges. Therefore, during the period 2007 till 2009 AAIB made a wide range of dialogue with their stakeholders through personal interviews, workshops, network meetings, and conferences in order to identify the main stakeholders and to understand their expectations which became at the core of AAIB's CSR plans, international frameworks and philanthropy. So, AAIB focuses on the interest of six primary stakeholders: 
shareholders, customers, employees, business, business partners, community, and environment. Understanding each stakeholder's needs and adding value to them by being innovative and setting key targets for improvements across all areas of the bank's performance became the center or the focal point to the achievement of sustainable growth. Figure 2 shows the stakeholders AAIB addresses in its strategy.

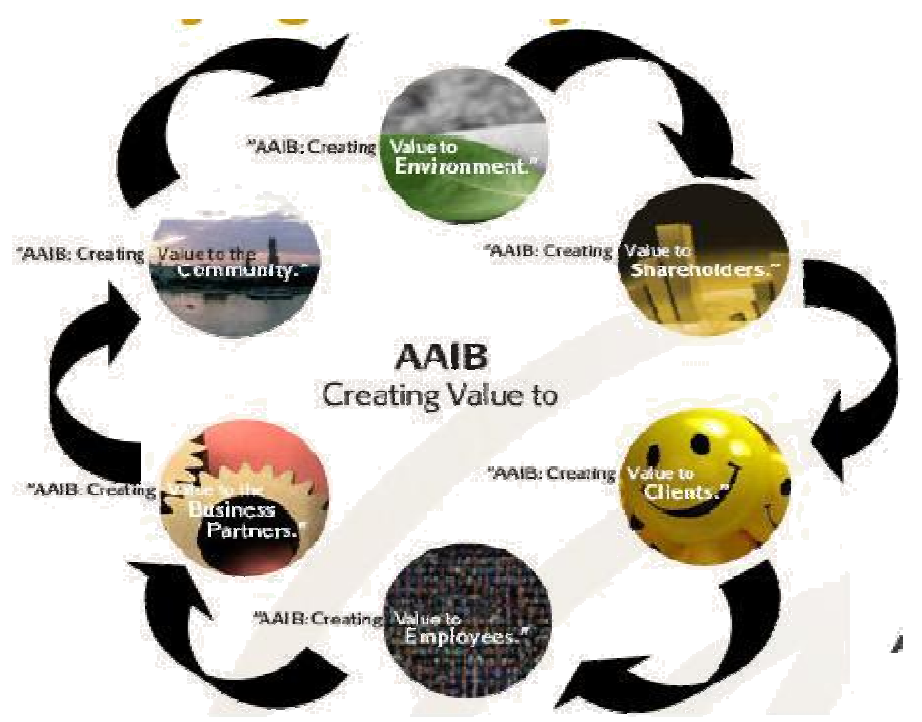

Figure 2: CSR Multiple Stakeholders' Model (AAIB, 2010: 23)

Moreover, repercussions of the $25^{\text {th }}$ of January 2011 revolution have to be accounted. More than a year had passed and all corporations and stakeholders have acknowledged the facts of its implications on the country in general and the business community in specific. AAIB had to stand against such circumstances to fend for its long history of CSR activities amid a blizzard of practices striving to manipulate the masses to win them over one side or conceal unfavorable truths. Thus, and AAIB held a first public press conference to identify its CSR practices in April 2011 that it had embarked upon from the beginnings of the millennium. AAIB acknowledged that its CSR activities had not been affected by the turn of events in Egypt, whereby it sustained its same level and scale of operations for its multiple stakeholders as discussed in the following section. The only variation appeared in allotting a slightly higher attention to the environment and the community so as to serve the higher purpose of enhancing and upgrading Egypt.

\section{Clients}

Clients are the main assets for any corporation without them it could not survive in the business market. For that reason, AAIB always seeks not only to meet customers' expectations but also exceed those expectations in order to make their customers delighted not satisfy only. Actually, AAIBs main goal is to get customers integrated in the bank as part of the banks daily life providing an exclusive experience across all contact points along with the distinguished financial products and services. AAIB turned from customer satisfaction to customer delight by developing ways to increase them such as Bilingual bank statements, an accessible corporate website, 
convenient and aesthetically pleasing branches are all designed to better the customer experience. Figure 3 shows highlights of such activities.

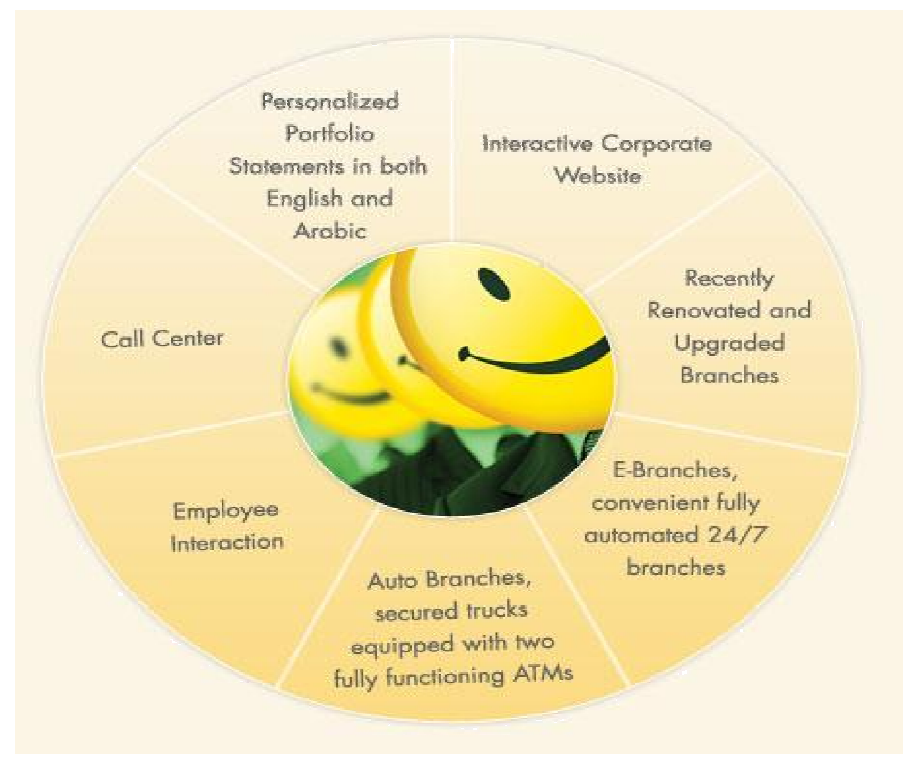

Figure 3: Clients as stakeholders for AAIB (AAIB IS 3, 2012)

\section{Environment}

Mazurkiewicz, P.A. (AAIB, 2010: 24) identified that ".... financial institutions investing in businesses that are financially, socially, and environmentally sustainable over the long term, is strategically smart and will guarantee the sustainability of their own business model. In banking, sustainability means adopting good standards for environmental and social risk management such as the EP and banking those firms and projects that are able to meet those standards. It is ultimately about creating better businesses. Firms that hold people, planet, and profit as core corporate values should succeed in good times as well as bad"

Actually, AAIB had another mindset that goes beyond materialistic achievements, to include other values such as governance, social inclusion, as well as environmental protection beyond the mere making and increasing of profits. This has been remarkably proved especially after the later worldwide financial crisis in 2008 (AAIB COP, 2011). On the 15th of January 2009, AAIB has adopted The Equator Principles (EP), to further demonstrate social, environmental, and moral considerations across different sectors of the economy, particularly through its vast network of corporate clients. The EP took four paths including: Policies and Procedures, EP Training, Peers Engagement, EP Reporting (AAIB IS 1, 2012). AAIB has a significant footprint toward the environment by minimizing resource use to better sustain the earth through the investment in the Green finance Programs. In 2008, AAIB started The E-Movement, which is an internal initiative of replacing staff monthly salary pay slip paper with e-statements in order to reduce time pressures, reduce paper consumption and enable employees to view their salary for any monthly duration they prefer. In 2009, AAIB 
established the energy efficiency by replacing the centralized electricity system with light control switches that required enhancing the employees' behavior to contribute to the institution's welfare. In respect to the continuance of value creation for the environment, AAIB launched in February 2009 the expenses committee to improve the bank's cost structure and operating targets, and replacing "the culture of excess" with "the culture of necessity" (AAIB Report, 2010).

In addition, on November 23rd, 2010 AAIB joined as a key partner in the annual

Investing in Egypt's Green Economy Conference; the event witnessed high financial sector engagement with the attendance of other sectors such as government officials, academic leaders and experts, civil societies, and private sector institutions (AAIB COP, 2011). Green Finance initiative is not only about AAIB's investments, but it goes beyond profit making to include a moral mission towards the Egyptian community. Consistent with AAIB's mission of continuously serving the Egyptian community; AAIB support others foundations and NGOs having the same objectives that matches AAIB's core CSR mission towards its community stakeholders. For instance, AAIB made a contribution to Takadom Kafr Shukr Foundation where located in Qalyoubia, to support the foundations wide ranged projects serving Kafr Shukr citizens (AAIB COP, 2011).

After the revolution, more increased attention had been directed to such initiative. For Example, under the theme, Love the Environment... Love Egypt, AAIB initiated in 2011 an environment-focused public awareness campaign that aims at educating the Egyptians how to preserve and protect the country's natural resources, i.e. a step towards Environment Sustainability(AAIB COP, 2011). Such campaign will be launched in an electronic and paper format to reach out the largest proportion of population.

\section{Community}

AAIB believes that no development would take place in Egypt, unless Health and Education are consistently and sincerely addressed and Egyptians deserve best Health and Education. Therefore, AAIB focuses on two basic pillars of human development, health and education in order to create value for the Egyptian community. To be that affect, AAIB initiated three major community programs: "We Owe It to Egypt" foundation, and the "Arab African International Bank Award" annual banking competition, bonding with Academia beyond the others cause marketing activities. The earlier foundation; established in January 2007 and registered with the Ministry of Social Solidarity; had strived to attain two objectives, namely the pooling and establishing of centers of excellence in health and education along with establishing core processes and stakeholder involvement to achieve and sustain development. AAIB contributes monetarily and also commits resources to train doctors, nurses and other hospital staff, renovate existing facilities and create a positive uplifting atmosphere. The main current projects that AAIB working in under "We Owe It to Egypt" are, 1) Cairo University Specialized Pediatric Hospital (CUPH); 2) The National Cancer Institute (NCI) and 3) Urology \& Nephrology Center of Mansoura.

The second initiative is "AAIB Award" which was inaugurated in 2003 to encourage undergraduate students to develop and present a new financial product or service that doesn't exist in the Egyptian market or improves an existing one. The initiative's objectives, are to enhance the knowledge of students and their understanding of banking and finance for the benefit of the economy, the development of some of the basically demanded interpersonal skills in the business field such as: planning, report writing and presentation skills and to foster teamwork and inter-disciplinary coordination. In 2011, seven universities have been participated in this competition with more than 150 students and 44 teams, 
comparing with the first year launched with one participated university.

The later initiative's objective is to develop a strong bonding relationship between the professional finance and the academia in order to maximize the interactions among different members in the community to build better Egypt and to attest the sustainable presence of the bank by AAIB's supporting and the sponsorship for several events such as AAIB Bonding with AUC and GUC research conferences and international workshops (AAIB COP, 2011).

In light of AAIB's CSR vision, AAIB supports and cooperates with different organizations active in several fields in Egypt such as health, culture, and education. In fact, AAIB is considered one of the most active promoters of community service organizations, AAIB's philanthropic activities fall into the following four categories as shown in figure 4 below.

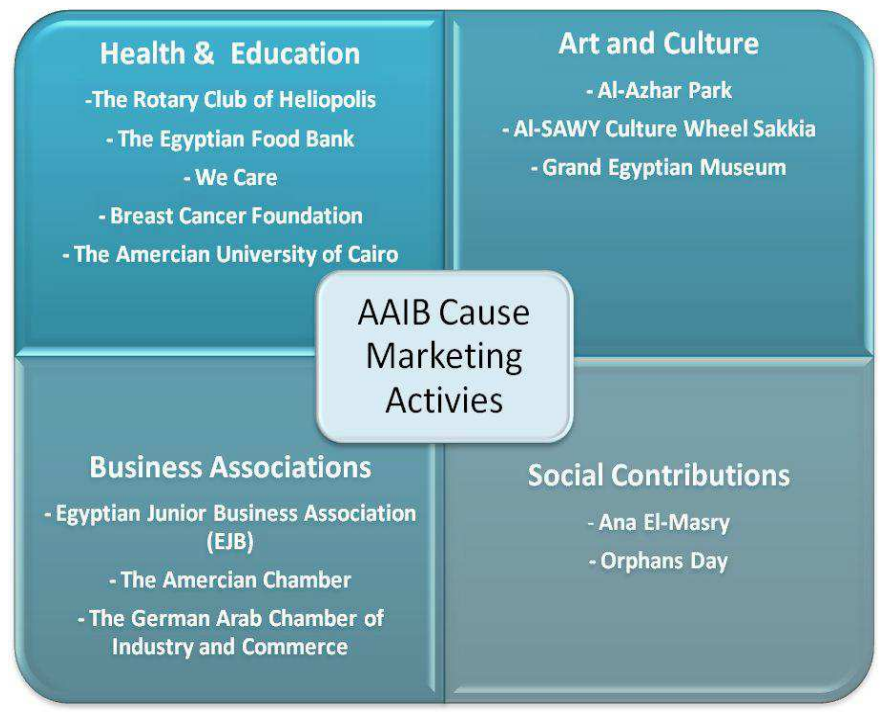

Figure 4: AAIB's cooperation for Community (AAIB, 2010: 40)

After the revolution; especially with the high corruption rates exposed; AAIB with its vast experience in the banking field had ventured into activating its earlier campaign to endorse different banks in the MENA region towards safe credit and lending policies. As such, interests of different interested stakeholders will be more protected and better, more secured investments will be undertaken. In addition,

\section{Employees}

AAIB is committed to align organizational growth with the professional and personal growth of all employees, and believes that rewarding employees is not only based on the monetary terms; whereby it leads to increasing the commitment and motivation of employees to become more innovative and productive. For that reason, AAIB has developed a 360 degree benefits to employees including material and nonmaterial rewards. The goal of this initiative is for AAIB's employees to enjoy a 360 degree beneficial cycle where all intellectual and educational investment in our staff pays back the bank with profits shares and returns, which in turn pays back those employees financially with attractive salary and bonus packages. The 360 benefits to employees divided in two basic sections 1) cash payment, AAIB believes the pay-to- 
performance culture increases the competition and motivation among employees in order to excel their performance which will be reward on in it and retains better employees, and 2) benefits.

AAIB believes in providing employees with ongoing improvements in the human resources structures such as developing their career needs, scholarship funds, house and education loans, medical insurance, rotation programs and last not least training programs that suit the background and experience of the new and the existing staff. AAIB strongly encourages the internal cultural shift from a closed to an "open environment" with ease of information flow through good and transparent internal communication such as bulletin, ongoing eannouncements, periodic internal publications monthly meetings and staff gatherings, outings and events like social and sports committee like Ramadan Football Tournament (the Holy Muslims' fasting month), casual day and AAIB in-house library in order to build better, more directed and efficient workforce. For example, on the 7 th of April 2010 AAIB launched the AAIBian blog the first blog in the Egyptian banking sector which became the voice for each employee where AAIB staff can share their information, innovative ideas and the latest topics as well as address their concerns in a purposeful friendly manner. (AAIB COP, 2011)

Additionally, AAIB encourage their employees to engage and involve in the bank's community projects through employees volunteerism programs (EVP). Employee participation and charitable contributions are valued as an integral part of the AAIB culture. Donating blood, time, expertise and money are all ways that AAIB employees have gotten involved in helping out there community.

After January 25th of revolution, a nationwide campaign took place to seek blood donations, to cover the dire need for the injured citizens. AAIB cooperated with a medical organization, Vacsera, to host a medical team at the bank premises. Blood donating took place from 10:00 am to $2: 30$ pm for one week. The campaign has witnessed a huge number from the employees who passionately wanted to support the revolution victims (AAIB COP, 2011).

\section{Business Partners}

AAIB places significant importance on its relations with business partners, taking it on its own account to protect, nurture and support such partners. AAIB's main belief stems from the fact that dealing with sound, reliable and reputable business partners will eventually stem in their corporate best interest. AAIB undertakes such goals by means of using high selection standards in selecting such partners along with providing equal opportunities for all competitors. Also, AAIB is keen on developing and nurturing long-term relations with its business partners, giving due attention to ethical practices and value that help in creating market soundness and supplement all that with prompt and due payments to its business partners.

\section{Shareholders}

Shareholders represent the main beneficiaries for AAIB as any other corporation to have an effective and transparent corporate governance framework and to provide the investors with complete and up-to-date information. AAIB differs in addressing such shareholders amongst others, avoiding singling them out as sole beneficiaries. Thus, AAIB works to protect shareholder rights and interests by maximizing returns earned via effective management of the bank's assets and continued growth of the bank's operations and profitability, while working on minimizing risks and maximizing the value of the bank by becoming an organization capable of generating income in any economic climate. AAIB conducts such goals 
through its Board of Directors (BOD), with its four main governing committees (namely: executive committee, audit committee, corporate governance committee and remuneration committee.

To sum up, AAIB follows the highest standards of business, environmental and ethical conduct in all of its endeavors both internally by practicing CSR as an institution, and externally through influencing corporate clients and business partners to practice CSR. AAIB is institutionalizing CSR through adopting a belief system with a structural approach to the bank's spheres of influence and conceptual stakeholders' framework that together outline AAIB's serious commitment and virtual boundaries of its CSR policy to create value for the stakeholders and community and to sustain responsible finance. The AAIB's spheres of influence include three main components: core business activities, voluntary contributions and public policy advocacy as shown in figure 5 .

The (core business activities) for the AAIB focus on how to integrate strategic CSR initiatives within its business practices in key functional areas and produce measurable through established a CSR unit to align CSR strategies and goals with that of the organization. For (voluntary contributions), AAIB made great efforts in institutionalizing its voluntary contributions to the Egyptian community in a manner that involves not only material contributions but also operational involvement to ensure concrete results. Therefore, AAIB focuses on two basic pillars of human development, health and education through three majors programs: "We Owe It to Egypt" foundation, the "Arab African International Bank Award" annual banking competition, and bonding with Academia beyond the others cause marketing activities. In the line of serving and supporting the Egyptian community as well as cooperating with others NGOs, AAIB made giant strides to improve the quality of Egyptian life through several activities in different fields such as arts, culture, education and health,...etc. In addition, AAIB always encourages their employees to engage the bank's community projects through employees volunteerism programs (EVP).

For (public policy and advocacy), AAIB made wide-ranges of dialogue with their stakeholders through personal interviews, workshops, network meetings, and conferences to understand the expectations and aspirations of its stakeholders. Furthermore, year 2010 has witnessed an active engagement for the bank in various events and situations that notarized AAIB's presence and its role in reinforcing the financial performance both regionally and globally (i.e. participation in the 15th Euro money Conference on September 2010 and Third Annual CSR conference; while hosting the 2nd roundtable for the UN Global Compact in coordination with the ECRC) (AAIB COP, 2011). In addition, on December 2010, AAIB has been published its first sustainability report entitled "Finance with Value Creation" which was the first sustainability report to be issued by a financial institution in Egypt. Consist with the AAIB public policy; year 2011 has witnessed the launch of a newly updated CSR section on AAIB's website. The new website is fully informative and linking all stakeholders, and strives to exceed all stakeholders expectations. 


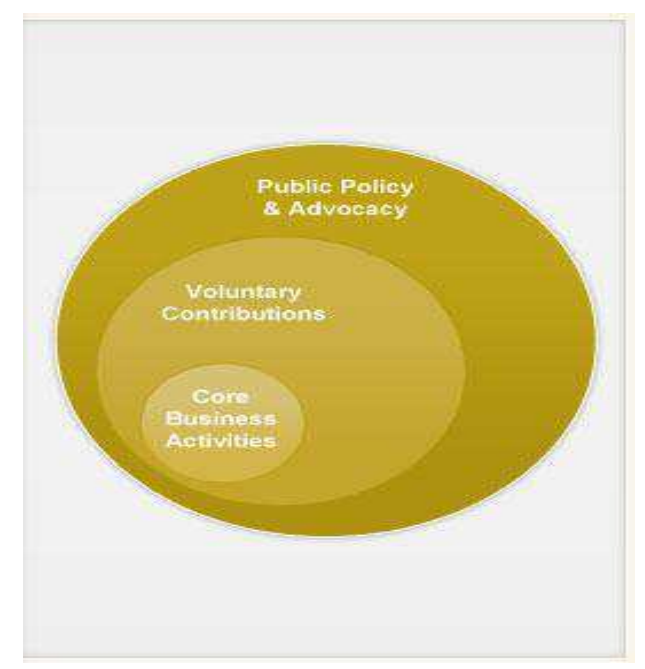

Figure 5: Spheres of CSR Influence of AAIB (AAIB, 2010: 15)

Finally, such successes postulate AAIB as a success story at the heart of a renowned ruthless industry for its fierce competition by relying and reformulating its strategies around concepts of sustainability, corporate social responsibility and multiple stakeholders' perspective. To continue its growth and success and to achieve shareholders satisfaction, a clear and efficient corporate governance framework has been established. Finally, AAIB stands as a unique banking and financial success experience in Egypt and MENA region. It had succeeded in embedding the CSR notion within the banking sector as a strategic cornerstone serving multiple stakeholders, by which evading the myth of profitmaximizing behavior of banks. Its efforts earned it the UN

Global Compact's nomination as one of the best 32 financial institutions for social responsibility and awareness of sustainable development in Egypt (AAIB Newsletter, 2011 and AAIB COP, 2011).Eventually, AAIB stands as a bank that enjoyed various reputable and highly recognizable global awards like:

[1] Best Bank Website Award

[2] The Banker Deals of the year

[3] Best Investment Bank Award 2011
[4] Century International Award

[5] Superbrands Award (AAIB COP, 2011).

\section{References}

1. AAIB, (2010), CSR : From Concept to Structure, CSR Unit Presentation, pp. 1-40, Cairo, Egypt.

2. AAIB COP, (2011), 4th annual Communication on Progress Report (COP), (April 11th , 2011), Cairo, Egypt, pp. 1-42.

3. AAIB Internet Source 1 (IS1), (2012), Green Finance, Retrieved on January $13^{\text {th }}$, 2012

at: http://www.aaib.com/CorporateSocialRes/G reen Finance.aspx

4. AAIB Internet Source 2 (IS2), (2012), We Owe It to Egypt, Retrieved on January $13^{\text {th }}$ 2012 at: http://www.aaib.com/CorporateSocialRes/ We Owe it to Egypt.aspx

5. AAIB Internet Source 3 (IS3), (2012), Customers, Retrieved on January $13^{\text {th }}, 2012$ at: 
http://www.aaib.com/CorporateSocialRes/C ustomers.aspx

6. AAIB Newsletter, (2011), October Newsletter, Global Compact "UN Global Compact": "Arab African" best financial institution for social responsibility and awareness of sustainable development in Egypt, (October, 2011), Cairo, Egypt-In Arabic.

7. AAIB Report, (2010), Sustainability Report: Finance with Value Creation, Cairo, Egypt.

8. Nassar, E., and Mandour, A. (2000), “The Role of Services Trade Liberalization on commercial banking sector", Annual conference of economic department, for service trade liberalization and its influence on Egyptian economy, April, 22, faculty of commerce, Ain Shams University.
9. Kapoor,S., and Sandhu, H.S. (2010), "Does it pay to be socially responsible? An Empirical examination of corporate social responsibility on financial performance", Global Business Review,

Vol.11, no. 2, pp.185-208.

10. Kotler, P. and Lee, N., (2005) “Corporate social responsibility: doing the most good for your company and your cause", John Wiley \& Sons, Inc., New Jersey, U.S.A.

11. Zeitoun, N. (2010), New CSR index tracks performance of listed companies on the Egypt Stock Exchange. Retrieved on January 19th, 2011 from UNDP Newsroom website: http://content.undp.org/go/newsroom/201 0/march/new-csr-index-tracksperformance-of-listed- companies-on-theegypt-stock-

exchange.en;jsessionid=a5BSFuj930-7 